\title{
HACIA EL PENSAMIENTO DE JUAN RUIZ DE ALARCÓN
}

LOLA JOSA

Universidad de Barcelona

A Rosa Navarro Durán

\begin{abstract}
Quiero que entiendan vuestras señorías que Sancho Panza es uno de los más graciosos escuderos que jamás sirvió a caballero andante [...], yo no le trocaría con otro escudero, aunque me diesen de añadidura una ciudad; y así, estoy en duda si será bien enviarle al gobierno de quien vuestra grandeza le ha hecho merced; aunque veo en él una cierta aptitud para esto de gobernar, que atusándole tantico el entendimiento, se saldría con cualquier gobierno, como el rey con sus alcabalas; y más que ya por muchas experiencias sabemos que no es menester ni mucha habilidad ni muchas letras para ser uno gobernador, pues hay por ahí ciento que apenas saben leer, y gobiernan como unos girifaltes; el toque está en que tengan buena intención y deseen acertar en todo; que nunca les faltará quién les aconseje y encamine en lo que han de hacer, como los gobernadores caballeros y no letrados, que sentencian con asesor. Aconsejaríale yo que ni tome cohecho, ni pierda derecho, y otras cosillas que me quedan en el estómago, que saldrán a su tiempo, para utilidad de Sancho y provecho de la ínsula que gobernare ${ }^{1}$.
\end{abstract}

He querido iniciar el presente artículo con este parlamento de don Quijote por lo que, en otra ocasión, comenté a propósito de la extrañeza del teatro de Ruiz de Alarcón como si de una cuestión cervantina se trata$\mathrm{se}^{2}$. Pero es que este fragmento hubiera resultado también más ilustrativo para empezar a celebrar el denominado programa de reformación ${ }^{3}$ trazado

\footnotetext{
${ }^{1}$ Quijote, II, 32. Edición, introducción y notas de Martín de Riquer, Barcelona, Planeta, $1975\left(5 .^{a}\right)$, pp. 831-832.

${ }^{2}$ Lola JOSA, «La 'extrañeza' del teatro de Juan Ruiz de Alarcón: una cuestión cervantina», América y el teatro español del Siglo de Oro. II Congreso Iberoamericano de teatro (Cádiz, 23 a 26 de octubre, 1996). Edición a cargo de Concepción Reverte Bernal y Mercedes de los Reyes Peña, Cádiz, Servicio de Publicaciones de la Universidad de Cádiz, 1998, pp. 153-167.

${ }^{3}$ Concepto con el que Elliott resume uno de los programas con el que Olivares pretende hacer resurgir a España de la sombría situación —en este caso- nacional. El
}

Rlit, LXIV, 128 (2002), 413-435 
por el conde-duque de Olivares, que no cualquier epístola laudatoria y servil, o poema, o tratado con los que se pretendió dar la bienvenida a quien resultaba ser el nuevo «arquitecto» ${ }^{4}$ de una deseada nueva España. $\mathrm{Y}$ es que don Gaspar, como muy bien nos informa John Elliott, quería ser el artífice de la restauración del edificio imperial, y para ello, una de sus «trazas» consistía en hacer del rey un modelo de reyes, y de la corte, una espléndida monarquía que fuera promesa de «aciertos grandes en las acciones» $\mathrm{y}$ «feliz gobierno de los reinos y vasallos» por haber sabido casar la profesión de las armas y de las letras: los «dos polos [...] que gobiernan todo $[\ldots]$ movimiento $[\ldots]$, pues juntos entre sí hacen una muy importante consonancia, ayudándose y dándose la mano en cuanto se ofrece» ${ }^{5}$. De esta forma, el primer ministro debía convertirse en el nuevo mecenas que velara por los talentos literarios y artísticos de Castilla y Andalucía, especialmente, como si de una cuestión de estado se tratase, ya que el resto del cuerpo social y político estaba seriamente enfermo ${ }^{6}$.

Y para lo que aquí interesa - circunscribir la producción alarconiana a unos referentes históricos que son tan necesarios para la obra del dramaturgo como determinantes para la historia de España-, voy a centrarme en los dorados años que van de 1621 a 1627.

Son en realidad los más interesantes del reinado de Felipe IV en lo que a la política reformista de Olivares se refiere, porque son aquellos en los que va buscando soluciones a los problemas que habían conmovido y preocupado a los arbitristas y a los círculos reformistas castellanos en las dos décadas precedentes. Es una época de efervescencia política e intelectual en la corte... ${ }^{7}$

Tiempo, además, en el que se consagra la escritura de Ruiz de Alarcón. Más allá de la mera casualidad de la que pudiera parecer fruto este primer dato, o incluso considerarse consecuencia de posibles servicios prestados por parte del autor hacia quien parece ser que vigiló por su carrera como

programa que promueve la resurrección de España en el ámbito internacional es el de reputación. De este modo, el historiador deslinda con claridad los dos propósitos políticos del gobierno del conde-duque. Vid. J. H. ElliotT y Ángel GARCía SANZ (coord.), La España del Conde Duque de Olivares. Encuentro Internacional sobre la España del Conde Duque de Olivares celebrado en Toro los días 15-18 de septiembre de 1987, Valladolid, Secretariado de Publicaciones de la Universidad de Valladolid, 1990, pp. 24-27.

${ }_{4}$ Así lo califica TIRso DE Molina en su Historia General de la Orden de Nuestra Señora de las Mercedes. Ed. Fray Manuel Penedo Rey, Madrid, Provincia de la Merced de Castilla, 1973, 2 vols., p. 475, tomo II.

${ }^{5}$ Palabras del propio rey en la «Autosemblanza» que escribe al hacer la traducción de la Historia de Italia de Guicciardini. En Cartas de Sor María de Agreda y de Felipe IV. Ed. Carlos Seco Serrano, Madrid, Atlas, 1958, p. 236.

${ }^{6}$ Cfr. J. H. ElliotT, El Conde-Duque de Olivares. El político en una época de decadencia, Barcelona, Crítica, 1991, p. 104 y capítulo III: «Programa de renovación», pp. 182-212.

7 Ibid., p. LVIII. 
letrado, hay que decir que se esconde un compromiso serio, y me atrevo a sostener que profundo, con las fuerzas con las que Gaspar de Guzmán emprendió su tarea de «saneamiento» socio-político. Tras una lectura de las comedias alarconianas, se advierte, con facilidad y por contraste, con cuáles pretendía abrir un diálogo con la corte de ministros, el monarca y con los más avisados espectadores, y con qué otras a divertir y experimentar con recursos escénicos. Por este mismo motivo, considero que el primer o último gran paralelismo entre el conde-duque de Olivares y Alarcón es el que la crítica haya silenciado u olvidado, durante tantos siglos, lo bueno que se escondía bajo las «sombrías» y "antipáticas» ${ }^{8}$ obras -en este caso- del dramaturgo. Y para justificar estas palabras nos debemos remontar hasta los arbitristas que buscaban una reforma para la Castilla de Felipe III, de cuyo espíritu es heredero, sin duda, el dramaturgo, porque el proyectismo ${ }^{9}$ de aquellos, reformadores es el hilo que deshace la madeja de la dramaturgia alarconiana; el que conduce a la comedia moral clásica, a Séneca, a Erasmo, a Shakespeare, al padre Mariana..., a toda intertextualidad que subyace en sus comedias; y, para cerrar el círculo, el que nos remite a Olivares.

Pero - qué decir tiene - el proyectismo de Ruiz de Alarcón no va a referirse a la economía, sino a la moral pública, como gran número de reformadores del reinado de Felipe III, quienes creían que el verdadero problema que ahogaba a España era la flojera moral y la relajación de costumbres. Es bien sabido que fue por aquel entonces cuando se empezó a hablar de España y sus males, y a tratar la decadencia de Castilla, en concreto, con una terminología médica, puesto que se representaba, las más de las veces, como cabeza y corazón de la monarquía. De ahí que la mayor porción de reformadores, «hombres con miras más amplias que las de sus compatriotas» ${ }^{10}$, se dedicaran a ejercer de médicos metafóricos respecto a la salud del reino. Muchos eran juristas, clérigos u oficiales, y también médicos, ciertamente, como Cristóbal Pérez de Herrera, amigo de Alarcón. Además de ser médico real y autor de unos cuantos escritos de medicina, proyectó su talante reformista en sus Remedios para el bien de la salud del cuerpo de la república (1610) y en los Proverbios morales (1618), tratado en el que nuestro dramaturgo se suma a la fila de los buenos arbitristas ${ }^{11}$ que alababan lo oportuno de la aparición del libro, con

\footnotetext{
${ }^{8}$ César Oliva / Francisco Torres Monreal, Historia básica del arte escénico, Madrid, Cátedra, 1994, p. 212.

${ }^{9}$ Conjunto de tendencias, actividades y escritos de quienes proponen proyectos para aumentar, especialmente, la hacienda pública. Con este término se denomina, asimismo, al arbitrismo de los siglos XVI y XVII. Vid. Michel D. GoRDON en «Morality, reform and the empire in seventeenth-century Spain», Il pensiero politico, 11 (1978), pp. 3-19.

${ }^{10}$ Elliott, El Conde Duque..., p. 108.

$"$ En todo momento dejo al margen, al igual que hace Elliott, a los charlatanes que propiciaron el tono despectivo con el que se empezó a utilizar la palabra «arbitrista».
} 
unas ya conocidas quintillas que vienen a ser la cabeza del hilo de lo que nos ocupa.

Los Proverbios fueron aprobados, además de nuestro Alarcón, por escritores como Salas Barbadillo, Valdivielso y Céspedes. Ni Lope, ni Tirso, ni ningún otro dramaturgo más ${ }^{12}$. Pero es que en el caso de Alarcón, visto bajo el prisma que estoy proponiendo, ¿extraña que así lo hiciera? En el dramaturgo existe una armonía entre ética y estética, y sólo cuando la primera ya no tiene razón de ser ante el desmoronamiento de la reforma de Olivares - la última esperanza-, deja de escribir; cuando el escepticismo y la desilusión se han apoderado de su pluma ${ }^{13}$. De ello son hijos los textos que dirige «al lector» en las ediciones que preparó, y es entonces cuando sólo le queda como motivo de satisfacción su ministerio en el Real Consejo de Indias; cuando decide desafiar, más allá de todo tópico y retórica, a un público-lector que, desde·1630, más o menos, se abandona, cada vez con mayor frecuencia, a comedias de enredos fortuitos y desenlaces demasiado felices ${ }^{14}$.

De vuelta con los Proverbios de Pérez de Herrera, cabe destacar, finalmente, que en la dedicatoria que escribe al príncipe Felipe, dice que éstos pretenden ser una herramienta para ayudar a quien deberá reinar; herramientas por lo que tienen de doctrina estoica, lo que nos obliga a volver con Alarcón y Olivares. En Cómo ha de ser el privado, Quevedo, inspirándose en el conde-duque -en la comedia, la máscara de ficción del ministro es el marqués de Valisero, anagrama evidente de Olivares-, viene a denominarlo el nuevo «Séneca español» ${ }^{15}$. Y nada ajena le podía ser esta calificación a don Gaspar, ya que siempre busca consuelo a sus cavilaciones y errores de estado, o desasosiegos espirituales - causados por la muerte de su hija-, en la filosofía estoica o neoestoica de la mano de Justo Lipsio ${ }^{16}$. Esta inclinación filosófica viene determinada, en buena medida, por la combinación en su carácter de ambición y melancolía, por lo que enfrentarse al mundo con fortaleza y resignación era la ecuación idónea que le permitía cultivar un juicio político con orden, disciplina y austeridad, y no abandonar a su rey, a pesar de que lo solicitó varias veces, aunque Felipe IV, a su vez, se lo denegara. Asimismo, una de las

12 Vid. la lista de los elogiadores que ofrece Cavillac en Cristóbal PÉREZ DE HERRERA, Amparo de pobres. Edición, introducción y notas de Michel Cavillac, Madrid, Clásicos Castellanos, 1975, pp. LXXI-LXXII.

13 Tengamos en cuenta que todo reformista, a pesar de la complejidad de los problemas de España, creía firmemente que se debía buscar una solución y que ésta saldría, por lo que la caída del régimen de Olivares les supuso la pérdida definitiva de toda esperanza. Vid. Elliott, El Conde-Duque..., p. 108.

14 Aubrun, La comedia española (1600-1680), Madrid, Taurus, 1981 (2. $\left.{ }^{\mathrm{a}}\right)$, p. 79.

${ }_{15}$ Quevedo, Obras completas. Edición de Felicidad Buendía, Madrid, 1966-1967, 2 vols., p. 625 , t. II.

${ }^{16}$ Elliott, El Conde-Duque..., p. 48. 
máximas más célebres de don Gaspar era: «los grandes hombres jamás alegaron autores, sino la razón» ${ }^{17}$. Y no otra cosa hacen los galanes protagonistas de los dramas políticos o de honor de Ruiz de Alarcón, rendir:

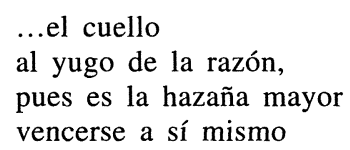

$(239 b, \mathrm{II})^{18}$.

Como dice El Tejedor de Segovia. Incluso con El dueño de las estrellas veremos a qué conduce la razón llevada al límite: a vencer la fatalidad aunque sea a costa del sacrificio. Además, a pesar de la explícita referencia a Las cartas a Lucilio, libro que lee el marqués de Villena de La cueva de Salamanca, el continuo sustrato de estoicismo en sus obras hace que la trama se tense por la presión de dobles fuerzas, que acaban por agrupar al elenco de personajes en enred́osos y embusteros, o bien, en ejemplo de una moral estoica. A este último grupo pertenecen, especialmente, los galanes principales - a menudo, máscaras del propio Alarcón-. Pensemos en el Garci Ruiz de Alarcón de Los favores del mundo, en el Juan de Luna de La industria y la suerte, o en el Don Juan de Las paredes oyen. Tampoco hay que olvidar a aquellos otros personajes que hacen de la amistad un acto de juicio y amor, como aconseja Séneca a Lucilio y encarna el Marqués Don Fadrique en Ganar amigos. Y es que esta corriente filosófica era más dada a establecer todo un arte de vivir que no a granjear reputación moral alguna. A Lucilio, a la vez que al repertorio de protagonistas del teatro que nos ocupa, se le aconseja que aprenda a contar más con sus propias fuerzas que con los dones divinos; que alcance la convicción de que, como individuo, puede desterrar cualquier accidente de su existencia y aspirar, gracias a la razón, a volverse invulnerable como los dioses; motivo por el que únicamente, en las obras alarconianas, se alcanza el desenlace a través del consenso de los protagonistas por aplicar razón y justicia - humana, muy humana $-{ }^{19}$ al nudo de enredos y traiciones. Más adelante lo veremos con El dueño de las estrellas.

Pero, antes, importa insistir en que el dramaturgo crea a partir de una doctrina que es la madre intelectual del gobierno de Olivares, como muy bien analiza Elliott, pues su política exigía severidad, obediencia y compromiso

\footnotetext{
17 Ibid., p. 48.

18 Juan RUIZ DE ALARCón, Obras completas. Introducción y nuevo estudio preliminar de Alba V. Ebersole, Valencia, Albatros Hispanofilia, 1990, 2 vols. Citaré siempre por esta edición, indicando entre paréntesis el número de la página, la columna y el volumen.

${ }^{19}$ Con esto me refiero a que se castiga errores y vicios - sean de reyes o tiranos, ministros o nobles - no condenables por el catolicismo, sino por una moral natural, por lo que el castigo pertenecerá siempre a los fueros humanos y no divinos, como sucede, igualmente, en Cervantes.
} 
social $^{20}$. El conde-duque anhelaba virtudes cívicas para lograr una sociedad moderna, y Alarcón lo plasma en la escena, pero no por servilismo -repito-, sino por formación. Ambos pasaron los primeros años de sus vidas fuera de la Península, cosa que no era frecuente entre la nobleza hispánica; además, como hijos segundones que eran, estaban destinados al estudio de la carrera eclesiástica, por lo que compartieron aulas universitarias en Salamanca, junto a las asignaturas de derecho canónico y civil -incluso don Gaspar fue rector de don Juan-. De estos estudios, les quedó la inclinación por construir estructuras lingüísticas de tipo legal ${ }^{21}$. Los dos, también, una vez fracasa la reforma, desaparecen de la corte, después de que el duque de Medina de Las Torres - yerno de Olivares - le consiguiera al dramaturgo el puesto de relator del Tribunal del Consejo de Indias ${ }^{22}$. A él dedica, por supuesto, sus dos ediciones. Pero transcribamos sólo un fragmento del proemio de la edición de 1634 quẹ el autor dedicó al ya, entonces, sumiller de corps de Felipe IV: «Proemio sea, no el vulgar de que importunado de amigos hago esta impresión, nadie lo ha solicitado, sino el deseo de publicar siempre lo que debo...» ${ }^{23}$. Y según Mira de Amescua, el deber que se tomaba Juan Ruiz de Alarcón en el arte de componer comedias era el hacerlo con «mucha doctrina moral y política» ${ }^{24}$. De hecho, referencias políticas se desgranan hasta de sus breves avisos a los lectores, como en el de la edición barcelonesa: «...no te arrojes fácil a condenar las que te lo parecieren, advierte que han pasado por los bancos de Flandes, que para las comedias lo son los del teatro de Madrid...» ${ }^{25}$. Si por «bancos» entendemos los «asientos» de los asentistas, nos situaremos frente a uno de los problemas más acuciantes para los reformadores de los últimos años del reinado de Felipe III: el de la moneda de vellón y el consiguiente sufragio del ejército de Flandes. Durante muchos años el gobierno español había estado dispuesto a sufrir la sangría económica a causa de Flandes mientras siguiera suponiendo el sometimiento de los franceses y la hegemonía del rey de España sobre toda Europa ${ }^{26}$. Aunque de nuevo, una vez más, con la llegada de Olivares se creyó haber encontrado una solución definitiva. Como reanudó la guerra y, según palabras suyas, «las obras heroicas en los reyes... no pueden ejecutarse sin hacienda» ${ }^{27}$, promulgó la Unión de Armas y la supresión de la

\footnotetext{
${ }^{20}$ Cfr. Elliott, El Conde-Duque..., pp. 286-287, 292-300 y 448-449.

${ }^{21}$ Para Alarcón, véase KING, Juan Ruiz de Alarcón, letrado y dramaturgo. Su mundo mexicano y español, México, El Colegio de México, 1989, pp. 105-109, y para Olivares, ElliotT, El Conde-Duque..., pp. 34-37.

${ }^{22}$ Juan RUIZ DE ALARCÓN, Las paredes oyen / La verdad sospechosa. Edición, introducción y notas de Juan Oleza y Teresa Ferrer, Barcelona, Planeta, 1986, pp. X-XI.

23 «Proemio», RUIZ DE AlARCón, Obras completas..., p. 4, II.

${ }^{24}$ «Aprobación del Doctor Mira de Amescua», Ibid., p. [3] s. n., I.

25 «Al lector», Ibid., p. 4, II.

${ }^{26}$ Vid. ElliotT, El Conde-Duque..., pp. 86-99.

27 J. H. ElliotT, La España imperial (1469-1716), Barcelona, Vicens Vives, 1996, p. 355.
} 
acuñación de vellón; dos medidas que venían a simbolizar el cumplimiento de la «primera etapa del programa de reformas del Conde-Duque, y dar esperanzas de ayuda para Castilla y para la restauración de la economía castellana» ${ }^{28}$. Pero antes, y a propósito de esto, tuvo que deshacer un entuerto mucho más importante ante los ojos de los reformadores: recuperar la figura del padre Juan de Mariana.

Efectivamente, gracias a los pasos del ministro de Felipe IV, se recuperó la obra y la voluntad del historiador que mejor testimonia las andanzas de la España del momento. Perseguido por el ministerio del anterior monarca, cabe apuntar que tuvo que sufrirlo por haber escrito, precisamente, lo que pensaba en torno a la inundación de Castilla con moneda de vellón ${ }^{29}$. Pero si la aceptación de Mariana por parte de la política olivarista supondría desprestigiar aún más el gobierno del oscuro Lerma, lo más importante es que con él se abría paso'en la corte a todo aquel que quisiera aportar consejo y ejemplo para la monarquía. Por este motivo, se le concedió una subvención para que imprimiera una nueva edición de su Historia de España, y hasta el joven rey le alentó para que prosiguiera escribiendo su obra ${ }^{30}$. Incluso hoy, después de la lectura de sus pasajes más comprometidos, es fácil sentir confianza en el pensamiento del jesuita, inclinado como estaba hacia posturas políticas extrañamente democráticas. Pero es que lo que le favorecía era el apoyo que continuamente buscó en la historia para argumentar sus propuestas, sobre todo, en lo referente a la monarquía. Era lógico, pues, que quien tenía el deber de educar a un rey -Olivares- buscara respuestas en la instrucción para príncipes que representaba el De Rege et Regis Institutione (1598). De ahí que don Gaspar protegiera al viejo reformista; de ahí, también, que Alarcón buscara en el padre Mariana amparo para sus dramas políticos, para encauzar, bajo consenso reformador, sus consejos para una buena república. Ahí están las intertextualidades, que nos lo dicen tan a las claras como las quintillas con las que se identificó con los Proverbios morales del otro reformista Cristóbal Pérez de Herrera.

Desde que fue coronado el hijo de Felipe III, era unánime la voz que proclamaba lo que el gacetillero cortesano, Andrés de Almansa y Mendoza, escribió: «siglo de oro es para España el reinado del Rey, nuestro señor, Felipe $I V{ }^{31}$. Pero más que una realidad, fue el empeño por parte de Baltasar de Zúniga y su sobrino Gaspar de que así se creyera, pues el triun-

\footnotetext{
28 Ibid., p. 362

${ }^{29}$ Me refiero a su Tratado de la moneda de vellón, en Obras del padre Juan de Mariana, Madrid, M. Rivadeneyra, 1854, 2 tomos; pp. 577-593, t. II.

${ }^{30}$ Elliott, El Conde-Duque..., p. 188.

31 Andrés DE Almansa y Mendoza, Cartas de Andrés de Almansa y Mendoza: novedades de esta corte y avisos recibidos de otras partes (1621-1626), Madrid, Imprenta de Miguel Ginesta, 1886, p. 53.
} 
fo incipiente del conde-duque supuso también la victoria de un clan y una causa: el programa de reputación. Ya el embajador de Mantua, poco antes de la coronación, aconsejaba que «el verdadero apoyo a esta monarquía a la que poco falta para venirse abajo consiste en mantener la reputación» ${ }^{32}$, refiriéndose, sin duda, al tipo de política exterior tradicional, seguida por todo estadista del siglo XVII. Pero en el caso de la España de Olivares se trataba de conseguir la unidad de intereses entre Madrid y Viena; en retener a Francia y finalizar, de una vez por todas, con la guerra contra los Países Bajos, a cambio de que la paz comportara la restauración de la supremacía de la institución real española. Además, con ello, se impulsaría la política de reformación interna - aludida al principio- por pretender asentar el país sobre cimientos económicos y fiscales más firmes. De este modo - pensaban tío y sobrino-, se movilizarían los recursos marciales que permitieran realizar la estrategia de la reputación.

Aunque, para conseguirlo, Olivares debía gobernar y organizar la propia Península con tácticas más racionales y eficaces. Esto comportó, a su vez, resucitar viejos problemas, ya que tuvo que sostener una lucha sin cuartel contra una burocracia formada por una nobleza en pugna, desde hacía siglos, contra la propia monarquía. Motivo por el que el primer y gran reto de don Gaspar y su clan era convertir a ministros y oficiales en hombres comprometidos con la voluntad y prestigio del rey. Después, la política exterior se desarrollaría con mayor fluidez. O eso se creía. Lo cierto es que con prontitud y a voluntad de don Gaspar, el escenario se convirtió en la mejor tarima desde donde proclamar que la España imperial volvía a inspirar confianza; lo que conllevó, al mismo tiempo, que Felipe IV acabara siendo visto «como sol» ${ }^{33}$, y que esta imagen del rey planeta se convirtiera en el principal tema de la maquinaria artística del reino ${ }^{34}$, sobre

${ }^{32}$ ElliotT, El Conde-Duque..., p. 66, nota 133.

33 Felipe, como sol que va saliendo,

y estos nublados viles esparciendo;

que como suele aparecer la aurora

por nubes revestida de oro y grana,

saliendo de la noche vencedora,

en fe del sol, la cándida mañana,

Felipe celestial sus reinos dora.

Versos de don Gonzalo de Córdoba, acto III de La nueva victoria de Don Gonzalo de Córdoba de Lope. En Obras de Lope de Vega. Crónicas y leyendas dramáticas de España y comedias novelescas. Ed Marcelino Menéndez Pelayo, Madrid, Atlas, 1970, p. 337a. Véase, asimismo, J. C. J. METFORD, «Tirso de Molina and the Conde-Duque de Olivares», Bulletin of Hispanic Studies, 36 (1959), pp. 15-57.

${ }^{34}$ Como muestra de que la denominación de Felipe IV como planeta se convirtió en un tópico, véanse las curiosas Obras varias al Real Palacio del Buen Retiro. Recogidas por Manuel de Gallegos, Madrid, María de Quiñones, 1637. Valgan como preludio las 
todo porque, en el anterior régimen, y según palabras de Baltasar de Zúñiga, la monarquía era «un cielo, sin luz; un sol, sin rayos; sin espíritu, un cadáver» ${ }^{35}$.

Zamora Vicente bien anotó el provecho que de estas circunstancias históricas supo extraer Lope de Vega ${ }^{36}$; luego ya vino a acatarse que fuera «el más grande poeta de la conformidad» ${ }^{37}$, entendida ésta por ser un teatro dirigido al pueblo, en un momento en el que - a pesar de ser otro el contexto al del siglo XIV y parte del XV - la política de la reputación olivarista necesitaba, como antaño, apuntalar la creencia en la figura del monarca. Por esta razón, la imagen ideal del rey de España que el condeduque había imaginado proyectar sobre su joven Felipe IV -y que el teatro supo recoger - ${ }^{38}$ estaba compuesta por las mejores cualidades de todos los anteriores reyes: «la astucia política de Fernando el Católico, $[\ldots]$ la gloria y triunfos del emperador Carlos V [...]. De su abuelo Felipe II [...], la impasibilidad, la sobriedad y el arte de gobernar...» ${ }^{39}$. Sin embargo, por la errónea identificación del teatro áureo de la primera mitad del XVII con el modo y voz de Lope, lo de la «conformidad» se ha creído también respecto a la comedia en general del Siglo de Oro, tal y como pretendió demostrar Reichenberger, quien concluyó que ésta era la manifestación

palabras de Manuel de Faria y Sosa en su «Aprobación»: «...la espantosa fábrica del Buen Retiro (aún así no bastante para esfera de nuestro gran Planeta Cuarto)...», fol. 2v. Asimismo, Elogios al Palacio Real del Buen Retiro. Escritos por algunos ingenios de España. Recogidos por Diego de Covarrubias i Leyva, Madrid, Imprenta del Reino, 1935.

${ }_{35}$ En Ellotot, El Conde-Duque..., p. 79. Pero volviendo a la reticencia noble hacia la monarquía, de sobra sabemos la guerra civil que se sostuvo en España, durante el siglo XIV hasta el triunfo de los Reyes Católicos, entre las fuerzas predominantes: iglesia, monarquía y nobleza. Aunque cabe decir que la abolición de la monarquía como institución política no era el objetivo, sino que lo que se pretendía era que la voluntad del rey cayera en manos, en este caso, de unas oligarquías nobiliarias. De ello surgió una aristocracia cada vez más poderosa y ambiciosa, como la que rodeó, por ejemplo, a Enrique II. De toda esta cruzada fue de donde nació la necesidad en la monarquía de buscar amparo y apoyo en el pueblo, y éste, a cambio, empezó a vislumbrar al rey como el único artífice capaz de terminar con los abusos y la anarquía en que los nobles tenían sumida a toda la sociedad. De aquí, también, el recelo y el odio que anidó en el corazón de la aristocracia hacia esa villanía, evidente enemiga de sus tretas. Pero con la asunción de los Reyes Católicos, el monarca, como jefe absoluto del Estado, vino a ser el emblema de la justicia y el orden.

${ }^{36}$ Alonso ZAMORA ViCENTE, Lope de Vega. Su vida y su obra, Madrid, Gredos, 1961, pp. 253 y ss.

37 Amado Alonso, «Lope de Vega y sus fuentes» en El teatro de Lope de Vega Artículos y estudios. Ed. José Francisco Gatti, Buenos Aires, Ed. Universitaria, 1962, pp. 193-218.

${ }^{38}$ Vid. ElliotT, «El Conde Duque de Olivares: hombre de estado», La España del Conde Duque..., p. 27.

${ }^{39}$ Elliotr, El Conde-Duque..., p. 184. 
dramática de la ideología del pueblo español ${ }^{40}$. En cambio, a diferencia de Lope, Alarcón no tiene ni una sola obra en la que el rey sea el eje alrededor del cual gire el mundo. $\mathrm{Y}$ es que nuestro dramaturgo no estaba imbuido en campaña propagandística alguna, aunque sí al lado de Olivares, que no es lo mismo. Al estar comprometido desde la ideología y el anhelo de mejora socio-política -móvil de su escritura, a pesar de su ironía y su genio para saber adaptar problemas de estado y de pensamiento al lúdico escenario de los corrales de comedia-, su visión de la política de la reputación indudablemente tenía que ser la de un ojo crítico.

Así pues, con Alarcón estamos frente a un autor que no quiere afianzar y «popularizar los conceptos de la ideología monárquica» y «exaltar la figura del rey en sus dramas» $\sin$ más ${ }^{41}$; lo que pretende es matizar ese absolutismo real, conseguido a lo largo de la historia y reivindicado, de nuevo, por don Gaspar. La monarquía que traza y propone su pluma es dialogante, en el más amplio sentido de la palabra, sobre todo, porque en sus repúblicas dramáticas las responsabilidades de Estado recaen sobre el privado, por lo que la figura del rey queda abierta, hasta las últimas consecuencias, a un continuo diálogo con la corte y los problemas que aquejan a su pueblo. Al respecto, no puede dejarse de lado el detalle de que con Olivares, por primera vez, el rey asistió a las reuniones parlamentarias tras un ventanuco por el que podía escuchar, de veras, todo lo bueno y lo malo que se debía negociar para su reino. Aunque, sobre el escenario, el conde-duque quería que el público viera cómo se ejercía la realeza personal ${ }^{42}$. Pero Ruiz de Alarcón, por lo menos, no lo cumple.

$\mathrm{Y}$ no lo hace por ser sus obras políticas hijas de la tradición del speculum principis, basada en preceptos y ejemplos extraídos de la historia para poder desarrollar un sólido ars gubernandi. Por eso se inspira en Del rey y de la institución real del padre Mariana:

He aquí, pues, en resumen, príncipe Felipe, lo que me atrevo a dedicar tal cual es a tu augusto nombre, sin que me mueva a ello otra ambición que la de hacerte un pequeño obsequio, fomentar el desarrollo de tus grandes virtudes y esclarecido ingenio, y, por estos mismos esfuerzos, merecer bien de toda la república. [...] [Como] no pueden faltarte preceptos excelentes y de gran filosofía, he pensado que no podrás dejar de confirmarlos, más y más, leyéndolos en este libro, y aun observando otros que me parecen de gran fuerza para determinar la conducta privada, y gobernar con acierto [...] Antes, empero, de entrar en materia, te ruego, Príncipe, que no tomes a mal mi trabajo y procures corresponder ya a tu buen carácter, ya a la nobleza de tus antepasa-

${ }^{40}$ Arnold G. ReICHENBERgER, «The Uniqueness of the 'Comedia'», Hispanic Review, XXVII (1959), pp. 303-319.

${ }^{41}$ Richard A. Young, La figura del rey y la institución real en la comedia lopesca, Madrid, José Porrúa Turanzas, 1979, p. 17.

${ }^{42}$ Elliott, El Conde-Duque..., p. 183. 
dos. Te suplico, ¡oh, Dios!, que favorezcas nuestros esfuerzos [...] ¡Ah!, oye con benignidad mi súplica... ${ }^{43}$

Veamos, pues, cómo Alarcón ayuda al conde-duque de Olivares a «convencer a Felipe de que la autoridad real era un arte que se tenía que aprender, y ofrecerle su guía a la hora de dar los primeros e inseguros pasos en ella» ${ }^{44}$.

Para ello, en primer lugar, se debe esclarecer un aspecto - ya apuntado- del pensamiento alarconiano que, si no, impediría el cabal entendimiento de sus propósitos. Se trata del porqué en sus obras el mayor médico de los males políticos es el privado, y no el rey ${ }^{45}$. Al margen de ser la realización artística de lo que en verdad acontecía en la ladera del devenir histórico del país, la explicación viene dada dentro del laicismo razonable de Ruiz de Alarcón, heredado del antiguo estoicismo, y que hace posible, asimismo, el análisis de cualquiera de sus comedias, sean políticas o no. En cuanto a lo que venimos refiriendo, nos interesa extraer de la filosofía estoica aquello que tiene de doctrina que reclama la unión del hombre con su dignidad, y que propone, justamente, al propio hombre como la única certidumbre posible y como nueva medida. Por este motivo, no se tiene en cuenta a la divinidad como rectora de un canon de vida ${ }^{46}$. Tal es así, que, bajo esta directriz de pensamiento, se convierte en mucho más fructífero el juicio de Octavio Paz en torno al arte dramático de Alarcón, al afirmar que su teatro busca «la dignidad, la cortesía, un estoicismo melancólico...» ${ }^{47}$. «El hombre, nos dice [...], es un compuesto, y el mal y el bien se mezclan sutilmente en su alma», por eso, en el universo alarconiano, «el cielo cuenta poco», y en él, nunca triunfarán ni «la pasión ni la Gracia; todo se subordina a lo razonable» ${ }^{48}$.

Hasta tal punto condiciona todo esto a los reyes alarconianos que la función del monarca por encomendación divina queda más que postergada, para, así, sin ninguna aureola de divinidad que haga ver al rey como «pla-

43 Juan DE MARIANA, Obras..., «Prólogo» a Del rey y de la institución real, p. 467a, t. II.

${ }^{44}$ Elliott, El Conde-Duque..., p. 184.

${ }^{45}$ Contrariamente a lo que pretendían inculcar Olivares y su corte: «Vuestra Magestad es médico desta república». Palabras propagandísticas de Jerónimo DE CEBALlos en su Arte real para el buen gobierno de los reyes y príncipes, y de sus vasallos (Toledo, 1623). Apud, ibid., p. 104. La diferencia entre Ceballos y Mariana, en cuanto a tratadistas de la monarquía, radica en la actitud crítica del segundo frente al conformismo con el régimen del primero. Por ello el jesuita arroja luz sobre Ruiz de Alarcón

46 Vid. María Zambrano, Pensamiento y poesía en la vida española, Madrid, Endymion, 1996, p. 60.

${ }^{47}$ Octavio PAZ, El laberinto de la soledad, México, Fondo de Cultura Económica, 1993 , p. 38

${ }^{48}$ Ibid., p. 39. 
neta», poner a prueba su condición humana. $\mathrm{Y}$ es que, con Ruiz de Alarcón, el verdadero drama del rey es no querer saber que ante todo es hombre. En este punto es donde la figura del privado se crece, pues es él quien le enseña - ya con ejemplos o con renuncias y abandonos, que no traiciones- a controlar el vaivén de sus pasiones, para que logre encontrar y fundar, «dentro de su heterogeneidad dolorosa» ${ }^{49}$, su unidad como hombre y rey.

Tengamos presente que, a raíz de la toma de Granada (1492), llega hasta don Gaspar la creencia de que la supremacía de España se debía al cumplimiento de un dictado divino, y que:

fue dicho ideal el que determinó la política exterior española de este período [...], y su realización fue considerada como una obligación personal del rey impuesta por la divinidad a la nación. Con tales empujes ideológicos no debe sorprendernos que se exalte tanto a la monarquía. El rey español y la nación española eran los más poderosos [...] y habían sido escogidos por Dios para una misión especial que estaban llevando a cabo bajo la guía divina ${ }^{50}$.

Pero como los principales aspectos que forjan el tema monárquico en Alarcón no se fundamentan, concretamente, en esta ideología que en torno a la institución real se fue fraguando a lo largo de la historia, y que aún condicionaba al régimen de Olivares, el dramaturgo llega al extremo de la advertencia para el buen gobierno con reyes que atentan contra la propia monarquía porque no son buenos como hombres. Capital delito si se tiene en cuenta que el poder monárquico se impuso, precisamente, por ser el hombre débil, por:

\begin{abstract}
haber nacido frágil y desnudo, es decir, de haber necesitado de los demás para [...] defenderse. [...] Observóse desde entonces que la exagerada malicia de los hombres se hallaba contenida por la majestad del rey [...], ligada por la severidad de las leyes y el temor de los tribunales, de tal modo que, por evitar cada uno en particular el castigo, se abstuviesen todos de cometer maldades ${ }^{51}$.
\end{abstract}

Sin embargo, ¿qué hacer si es el propio rey quien no está libre de cólera y odios, y no sabe mirar «con igual amor a todos los que viviesen debajo de su imperio»? ${ }^{52}$ Es entonces cuando se le debe destronar o asesinar, según consejo del propio Juan de Mariana, ya que de rey ha pasado a ser tirano. $\mathrm{Y}$ cuando se convierte en tal, es porque «hace consistir su mayor poder en poder entregarse desenfrenadamente a sus pasiones», porque toma por medida de sus desmanes «no la utilidad pública, si no su propia utilidad,

\footnotetext{
49 ZAMBRANO, op. cit., p. 61.

50 YOUNG, op. cit., p. 14.

${ }^{51}$ MARIANA, op. cit., pp. 468b-469a, t. II.

${ }^{52}$ Ibid., p. 469a.
} 
sus placeres y sus vicios» ${ }^{53}$, como nos recuerda, por ejemplo, el rey-tirano de Creta de El dueño de las estrellas:

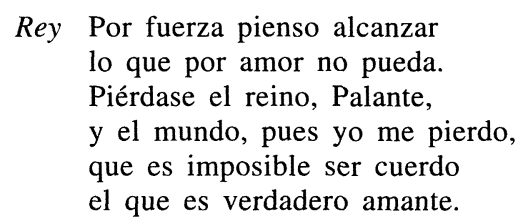

(66c, II)

Del monarca, prosigue diciendo el padre Mariana:

\begin{abstract}
es bien sabido que no hay nada que perjudique tanto la justicia como la ira, el odio, el amor y los demás defectos del alma... [Pero], ¿quién se ha de atrever a castigar los yerros de un príncipe que es dueño de las armas del Estado y lleva en la punta de la lengua, como dijo Aristóteles, la vida y la muerte de los ciudadanos? [...] ¿Ignoramos, por otra parte, que al llegar el hombre al poder es su propio adulador y mira siempre con benignidad sus propios hechos? Contéstese a esto que como no hay cosa mejor que la dignidad real cuando sujeta a leyes, no la hay peor ni de más tristes resultados cuando libre de todo freno. [...] ¿Quién no conoce y confiesa que es muy difícil contener con leyes las fuerzas y el poder de un hombre en cuyas manos están concentrados todos los medios de que dispone la república? ¿Cómo se ha de evitar $[\ldots]$ que no lo remueva todo y lo trastorne? ${ }^{54}$
\end{abstract}

En el caso de El dueño de las estrellas, se evitará con el sacrificio del privado - Licurgo- - que renunciará a su propia vida para no ultrajar la institución monárquica con su más que obligada venganza, ni tampoco vivir difamado por un tirano que pretende seducir a su esposa. Recordemos versos de su último parlamento:

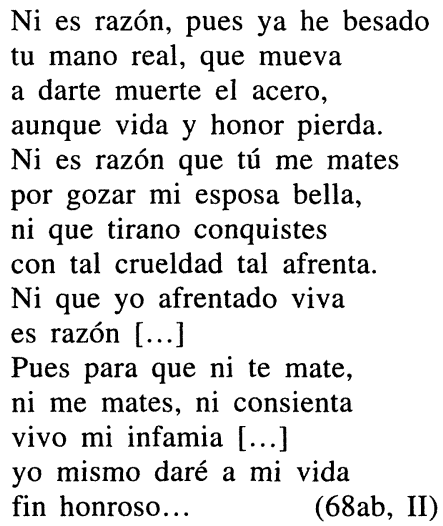

${ }^{53}$ Ibid., p. $477 \mathrm{~b}$ y $479 \mathrm{a}$.

${ }^{54}$ Ibid., p. 470 b. 
Garci Ruiz, otro privado, pero en este caso de la primera edición de las comedias de Alarcón — Los favores del mundo-, profería ya la siguiente queja acerca de su príncipe:

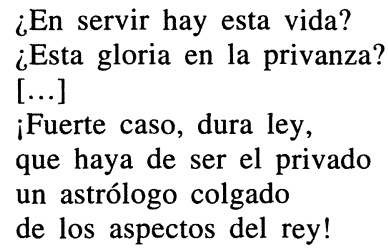

El motivo de su disgusto es el mismo que el de El dueño de las estrellas: el deseo desenfrenado y caprichoso del rey que, además, en el caso de Garci Ruiz, le obliga a sufrir constantemente cambios de fortuna, peripecia aprovechada para conferir a la obra comicidad. Pero a pesar de que Los favores del mundo, estructuralmente, sea una comedia de enredo, su final, en cambio, queda abierto para aquellos espectadores o lectores conscientes de la postura reformista de Alarcón. Representada antes de $1622^{55}$, durante los primeros años del movimiento reformador, ¿quién dudaría de ese desenlace lleno de presagios, en el que se sugiere que el príncipe no renunciará a su deseo por Anarda, aun siendo esposa de Garci Ruiz?

Este final, que en realidad es un principio, era suficiente para desconcertar al público madrileño, conocedor de los finales de las obras de Lope de Vega, Mira de Amescua, Tirso de Molina o cualquier otro ${ }^{56}$.

Asimismo, Garci Ruiz, aunque no llegue al extremo del suicidio para evitar graves problemas de Estado - pues el género impide al personaje soluciones drásticas, por lo que el desenlace, en apariencia, se alcanza gracias al desenredo de los equívocos-, será capaz de imponerse con arrojo al poder divino, que, si bien en la obra se representa con Fortuna y Amor, ante el final abierto de la comedia quien se nos revela como el único artífice de la suerte de los protagonistas es la figura del futuro monarca. Y ejemplo de la obligación con la que se tiene que rendir a los deseos del príncipe son estos fragmentos de dos monólogos de Garci Ruiz:

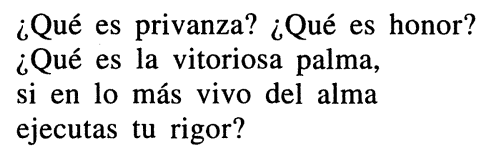

${ }^{55}$ RUIZ DE ALARCÓN, Las paredes oyen / La verdad sospechosa. Edición, introducción y notas de Juan Oleza y Teresa Ferrer, Barcelona, Planeta, 1986, p. XXXIII.

56 VEVIA ROMERO, «La diferencia en el teatro de Ruiz de Alarcón. Análisis semiótico de la obra Los favores del mundo», en El teatro mexicano visto desde Europa, Presses Universitaires de Perpignan, CIRILAUP, 1994, pp. 65-73, p. 68. 


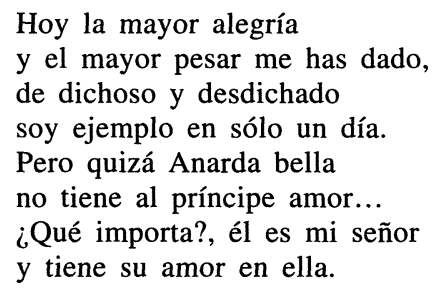

Hoy me vio el príncipe, y hoy me vi al más sublime estado de su favor levantado, y ya derribado estoy en un infierno profundo de temor y de ansia fiera. Paciencia, de esta manera son los favores del múndo. $(23 \mathrm{~b}, \mathrm{I})$

$\mathrm{Al}$ mismo tiempo, es lógico que sean muestra de la voluntad escindida de García. En el primero de ellos, resuelve renunciar a su amor por Anarda porque acaba de descubrir que el príncipe «muere» por ella. Y ante la duda de a quién amará la dama, prefiere que «la lealtad» «venza al amor» (19b, I). Matado el deseo, ejecutará las órdenes del príncipe convencido de cumplir con su deber. Pero un altercado con don Mauricio hará tambalear su resolución: García, obligado a vigilar la calle donde vive Anarda para que el príncipe, sin ser visto, pueda hablar con ella, encuentra al conde. Éste viene a vigilar la casa de la dama para que nadie se acerque a ella, y menos aún García, de quien está celoso. Así, movidos, ambos, por el deber que se imponen, ninguno renuncia a permanecer en la calle de la amada Anarda. Garci Ruiz, fortalecido por servir al príncipe, osa desafiarle y, al no ceder Mauricio, le hiere. Pero cuando el príncipe se entera de lo ocurrido, no vacila en reprender la imprudencia de García, por haber atentado contra uno de sus vasallos. Así, el desventurado caballero vuelve a verse atrapado en «confuso laberinto» (17a, I). Entonces es cuando pronuncia el segundo fragmento transcrito del monólogo del segundo acto.

En él, a diferencia del anterior, se pregunta si valdrá la pena correr semejante suerte «en servir» al que, por «agradar», ofendió (23b, I). Él, que por no matar a don Juan - para limpiar su deshonra - gana el favor del príncipe, y que, por servirle, hiere a Mauricio y encima pierde su favor, ¿ha de tener «esta gloria en la privanza?» (23b, I). Pero como no sólo se debe leer el significado de la obra a través del texto, sino también mediante su estructura y lo que con ella se alude, lo más grave es contemplar cómo un príncipe se ensaña con su privado en lo tocante a honor y justicia, y luego, paralelamente, descubrir que la paz del reino depende de la voluntad de una mujer que juega su baza contando con la debilidad de carácter del mismo príncipe. 
El caso es que Anarda le dice a García que le necesita para que vele por su honra, llegado el momento de que su alteza no quiera corresponder a los juramentos que de amor le ha hecho - aunque semejante petición sea un enredo que lo único que persigue es despertar el interés del vilipendiado Garci Ruiz-. Por otro lado, el príncipe, en un soliloquio, duda sobre qué hacer ante otra petición que le ha hecho la dama. Y es que cuando Garci Ruiz acomete contra Juan, lo hace ante la presencia de Anarda, y el príncipe, que lo observa todo desde la lejanía, lo interpreta como un lance de amor. Ella, que sabe que éste ha sido espectador de tal escena, finge estar ofendida y le implora que prenda a García por haber sido «descortés» y «grosero» y haber dado pie, a quienes «están / buscando qué murmurar» $(9 \mathrm{~b}, \mathrm{I})$, a que la crean liviana, por ver atacar a su lado a un hombre como don Juan. Lo cierto es que la discreta dama desea que prendan al galán porque, como sabe que Garci Ruiz es «forastero», puede marcharse de un momento a otro, en cambio, prisionero del rey, era más que probable que no saliera de Madrid. Traza finísima que propiciará todo el tejido de la trama, a la vez que es el motor de la voluntad de un príncipe que, por amor, una vez más, se cree con licencia para removerlo todo y todo trastornarlo, tal y como advierte el padre Mariana.

Volviendo al referido soliloquio del príncipe, es el punto de encuentro de la comedia en el que se cruzan el amor y la privanza como conflicto en la vida de García. A partir de aquí y a lo largo de la comedia, si los favores reales se ven fomentados, como compensación irónica pierde todo tipo de esperanza respecto al amor que profesa a Anarda, y viceversa. Y un avance de esta oscilación es, precisamente, la duda que tiene el príncipe de si cumplir «el [...] gusto / de una mujer» $(14 \mathrm{~b}, \mathrm{I})$ y agraviar «a tan heroico varón», o bien, mostrarse «poco amante» y «sufrir de Anarda el rigor», evitando «dar nota de inconstante» $(14 \mathrm{~b}, \mathrm{I})$ a su privado. Después de dudar, sin embrago, el príncipe reacciona tal y como esperaba Anarda...

La crítica al poder real, a la vulnerabilidad de un «hombre humano» que, por ser monarca, se albergaban en sus manos las «dichas» «del mundo lisonjero» (Los favores..., 26c, I), hemos dicho que se prolonga hasta El dueño de las estrellas. Pero el hecho de que esta obra pertenezca al género trágico nos obliga a deducir que el conflicto político tiene que ser en ella mucho más profundo y comprometido. A propósito de eso, leamos primero el siguiente fragmento:

En el teatro de la mayor parte del siglo XVII europeo existe una convergencia cuyo significado es imposible exagerar. Para el dramaturgo barroco, sea español, neerlandés o francés, sea católico o protestante, produzca obras clásicas o irregulares, el elemento perturbador es siempre el individuo y el orden no se restablece hasta que el individuo está encajado bajo la autoridad de un abso- 
luto, ya sea en el plano religioso o en el plano social, por su libre elección o por la fuerza, con su sacrificio o con su castigo ${ }^{57}$.

En El dueño de las estrellas, al rey se le superpone la figura del tirano y, paradójicamente, la de ser ese individuo perturbador que deberá terminar encajado bajo una autoridad absoluta que, en la obra, como demuestra Licurgo, es la afirmación de la razón como timón del destino humano -recordemos cuál es el elemento que conforma la estructura anafórica de su discurso final: «no es razón»-. El suicidio del privado es un reproche y un desafío al rey y a la institución que representa, pues su muerte no es sólo la del privado, sino la de un hombre honesto que con su renuncia a la vida logra mantener la virtud ante los ojos de su sociedad, ya que si el monarca es el artífice de la fortuna de sus vasallos - como resulta serlo, a su vez, en Los favores del mundo-, con su muerte voluntaria, Licurgo demuestra deshacerse «de la Fortuna con la máxima celeridad» ${ }^{58}$. Según Séneca — que tanto anima los textos de Ruiz de Alarcón-, el suicidio es el acto libre por excelencia del que el hombre es capaz; un acto noble que supone la culminación del reconocimiento de que la integridad moral propia está en peligro. Por ello no es sólo una acción heroica, sino acorde con la razón. ¿O acaso hubiera sido más digno vivir como un esclavo del rey, permitiendo que éste disfrutara de su esposa cuando quisiera?

...para romper las barreras de la servidumbre humana [...], la misma razón te advierte morir de la manera que puedas [...]. Es cosa indigna vivir de lo robado, pero morir de lo robado es cosa sublime ${ }^{59}$.

Es cierto que en esta tragedia se produce una inversión inesperada, ya que el rey debería haber poseído el talante del privado-vasallo, y Licurgo haber sido adornado con las pasiones del monarca. Pero Alarcón, de nuevo, da muestras de querer intensificar al máximo la creencia en la responsabilidad individual y en la acción humana por encima de categorías sociales: «No vayas a creer que sólo los grandes caracteres tuvieron esta fuerza $[\ldots]$, hombres de condición vilísima, con ímpetu grande, se evadieron para el inmortal seguro» ${ }^{60}$. Aunque, habiendo leído al padre Mariana y observando cómo el De rege actúa en los dramas políticos del dramaturgo, ¿por qué suicidarse el valido si se puede matar al tirano física o institucionalmente? Alarcón seguirá íntegramente el discurso de Juan de Mariana en

\footnotetext{
${ }^{57}$ A. GÉRARD, «Pour une phénoménologie du baroque littéraire. Essai sur la tragédie européenne au XVIIe siècle», Publications de l'Université de l'Etat à Elisabethville, V (1963), pp. 25-65, p. 61 .

${ }^{58}$ Consejo de Séneca a Lucilio. Cartas a Lucilio, VIII, LXX. Obras completas. Introducción traducción y notas de Lorenzo Riber, Madrid, Aguilar, 1949, p. 568b.

${ }^{59}$ Ibid., pp. 568b-570ab.

${ }^{60}$ Ibid., p. 568b.
} 
La amistad castigada. Con El dueño de las estrellas, en cambio, para no romper con la lógica del castigo al poder propuesta por Séneca, cumple con la advertencia que el maestro hace a Lucilio: más belleza hay «cuanto con mayor honra aprenden los hombres a morir que a matar» ${ }^{61}$. Pero, sin embrago, en el doble conflicto que sostiene con otro personaje, Teón, sí que optará por matar al tirano.

Retomando el hilo de la trama de la tragedia, se abre con el rey consultando el oráculo de Apolo que le pronostica que, para que en él y en su reino impere el orden y la paz, pida a Licurgo «el árbol venturoso» (38, II). Severo, padre de Diana - futura esposa de Licurgo-, será el encargado de encontrar a nuestro protagonista por mandato real. Y la primera fisura en la figura del monarca (entre el rey-planeta y el humano-rey) se produce en la escena siguiente, cuando a solas, con Palante, le confiesa que ha enviado a Severo para poder filtrarse en la cámara de su hija.

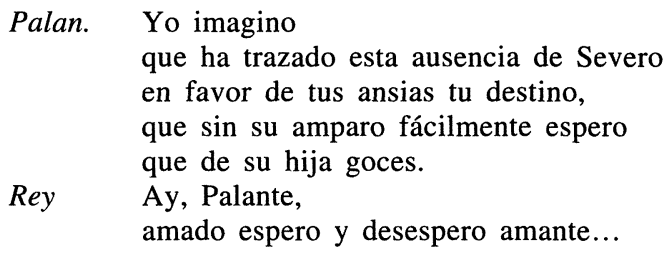

La fusión de las dos pasiones - política y amor- en el rey durante las dos primeras escenas anuncia las leyes afectivas de la tragedia: todos los personajes, a excepción de Licurgo, se moverán por el impulso de las dos fuerzas, y si sólo amor les mueve, como a Diana o a Marcela, se servirán de símiles políticos para justificar sus acciones. La primera dama denomina a su honra «razón de estado» (47, II), y Marcela, a vista de las intrigas y enredos del rey, cobra coraje para crear una pequeña comedia de enredo - todo el tercer acto- para frustrar el amor que Licurgo siente por Diana. Como preludio al clímax de la tragedia, próximo al desenlace, pronuncia en monólogo un soneto que justifica los conflictos pasionales de los hombres a semejanza de los dioses ${ }^{62}$ :

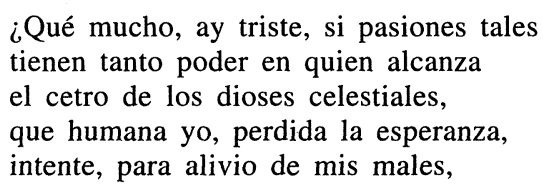

${ }^{61}$ Ibid., p. 569b.

62 Apréciese el paganismo en Alarcón como recurso para reflexionar sobre la fatalidad o el destino trágico del hombre. Remito, especialmente, a La industria y la suerte y Los favores del mundo, además de sus comedias de transición entre la comedia de enredo y la de caracteres. 
Lo curioso es que, escena seguida, humano-rey emprende su último intento de penetrar en los recintos de Diana. Es entonces cuando ya amor y venganza se apoderan, definitivamente, tanto del monarca como de sus súbditos, por aquello de que de tal señor, así serán sus vasallos, como rezaba una de las máximas de los reformadores. En el tercer acto, igual que hizo con Severo en el primero, el monarca planea, por el mal consejo de Palante - personaje que encarna a los intrigantes cortesanos contra los que arremete Alarcón-, alejar a Licurgo para satisfacer sus deseos con Diana.

Mientras, antes de que Severo lo encuentre, Licurgo, con un disfraz de rústico y bajo el nombre de Lacón, pasa de la corte a la aldea. Escondido en la sierra, convive con villanos que le consideran un justo defensor de sus problemas. Pero antes de que Severo lo encuentre, Licurgo, bajo la identidad de «Lacón», sufre de manera premonitoria lo que, más tarde, tendrá que sufrir también con el monarca: un noble, Teón -en el segundo acto sabremos que es el hermano de Diana-, se presenta en el pueblo y viola la honestidad de Menga, esposa de Coridón, el villano gracioso. Lacón sale en defensa de su amigo denunciando la injusticia, y Teón le contesta:

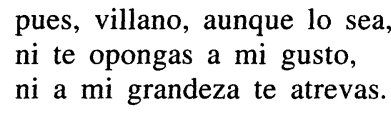

(41a, II)

Pensamiento idéntico motivará al rey a atreverse a emprender acciones igualmente injustas y perversas por el abuso de poder. La escena con Teón finaliza con un enfrentamiento entre ambos, y con la promesa, por parte de Licurgo, de vengar su ofensa. La cumplirá en el último acto, cuando abandona su atuendo de Licurgo y retoma el disfraz de Lacón sólo para matarlo. Con su muerte no sólo limpia su honor, sino el de todo un pueblo que ha sufrido su tiranía. Episodio paralelo al que Licurgo sufre con el rey. Con la muerte del noble, Licurgo desahoga gran parte de la venganza que con el rey no hará por decidir realizarla de otro modo, como se ha demostrado. En cambio, la muerte de la tiranía de Teón es símbolo de las muertes de todos aquellos que ostentan su poder sin respetar al pueblo, a la sociedad que rigen ${ }^{63}$. El paralelismo entre las dos tiranías, entre las dos acciones que protagoniza Licurgo está dispuesto por contraste - proceder dramático propio de Alarcón-, y lo importante de esta técnica, su

${ }^{63}$ Por parte de los servidores del rey también surgen comentarios despectivos hacia los villanos:

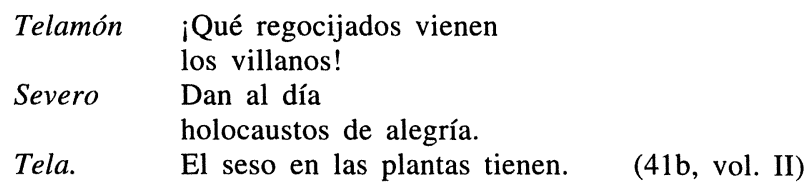

Comentarios confrontados y combatidos con el sentido democrático que en todo momento caracteriza las decisiones, parlamentos y acciones de Licurgo. 
trascendencia teatral es que permite interpretar que lo que se frustra en una - por tratarse del poder real $\mathrm{y}$, por lo tanto, requerir una venganza más «sublime»—, se realiza en la del ámbito del duelo entre nobles. Sutil resolución a la que se añade el autoaniquilamiento de Licurgo ante la imposibilidad - por su propio código deontológico - de matar al rey. Un rey que Alarcón salva sólo por el amor que le profesa Diana.

Ambas acciones, además de estar engarzadas por el parentesco entre Teón y Diana y por la efigie real - Licurgo no quiere tenerla hasta no haber vengado su honor, ni tampoco casarse con Diana hasta no haber merecido la insignia-, lo están por la dualidad nobleza-villanía en la que vive Licurgo y que, por otra parte, le confiere una amplitud de miras políticas que complementa su papel de gobernador. Como Lacón, juró venganza a Teón, y vestido de villano la cumple, al tiempo que es fiel al juramento hecho al rey de no permitir ser ofendido y no ser vengado. Vestido de noble, en cambio, venga el deshonor real. Una ofensa que cubre tanto el plano social como el personal, como en el caso de Teón. Este rey es capaz de crear intrigas y dejar perder el reino por satisfacer sus apetitos, y, precisamente, por ser rey, Licurgo sabe que su honor como esposo está ofendido, pues, aunque no lograse tocar a Diana por llegar él a tiempo,

$$
\begin{aligned}
& \text {...lo que intentan } \\
& \text { los reyes, ejecutado } \\
& \text { el vulgo lo considera. }
\end{aligned}
$$

Las palabras de Vitse de que con Alarcón sus personajes no corren ningún riesgo trágico son ciertas excepto en esta tragedia. Licurgo está desafiando continuamente a su propia suerte, luchando con ella para que no le conduzca al final irreversible de atentar contra la corona. Y por encima del amor, decide vengar al pueblo del servilismo a que lo somete Teón, a pesar de ser su futuro cuñado. La lucidez heroica de Licurgo consiste en romper con la dualidad oracular que dirige sus pasos a lo largo de la obra. El aviso de «la razón te acompaña» (40, II) con el que alienta a Coridón ante la injusticia de Teón, es lema de un personaje que asume someterse al absolutismo, pero sin que éste viole la integridad de los súbditos. De ahí su muerte.

La tragedia se cierra con unos versos del rey - palabras que demuestran la purgación de las pasiones que ha sufrido al presenciar la autoinmolación de su privado - en los que proclama la «fama eterna» (68b, II) para Licurgo. Con esta obra Ruiz de Alarcón se nos ha mostrado fiel a su talante reformista y también, cómo no, a la dinámica barroca por forjar una «voluntad de resolver las antinomias que oponen el individuo a la autoridad con vistas a restablecer la armonía de un orden ideal» ${ }^{64}$.

${ }^{64}$ GÉRARD, op. cit., p. 43. 
Para finalizar, quisiera decir, por un lado, que lo que se ha demostrado con El dueño de las estrellas, en otros trabajos lo haré con sus dramas políticos: Ganar amigos, La amistad castigada y Los pechos privilegiados. Y, por otro, que toda investigación en torno a Ruiz de Alarcón tendría que ser incitada por la certeza de que es limitadísimo jugar sólo con los tópicos ideológicos de la Inquisición y demás imposiciones áureas, o los de la crítica biográfica. Tampoco se puede hacer del análisis de un dramaturgo del siglo XVII tan solo un mero inventario de técnicas; hay que ver hasta qué punto se pretende romper y crear un orden nuevo de realidades aunque sean pequeñas. Sobre todo, repito, al tratarse de Alarcón. Porque detrás de él hay un estímulo que no le consiente satisfacerse en el solo acto creador. Existe el impulso de intensificar la mirada del oyente dramático ante la verdad, en oposición a toda consideración mundana. Esto es lo que escribe para la escena, «y con este instinto se alía, no sé si decir que paradójicamente, el gusto por la reticencia, testimonio siempre de buenas maneras e instrumento inapreciable para el arte literario» ${ }^{65}$.

\section{BIBLIOGRAFÍA}

Almansa y Mendoza, Andrés de, Cartas de Andrés de Almansa y Mendoza: novedades de esta corte y avisos recibidos de otras partes (1621-1626), Madrid, Imprenta de Miguel Ginesta, 1886.

Alonso, Amado, «Lope de Vega y sus fuentes» en El teatro de Lope de Vega. Artículos y estudios. Ed. José Francisco Gatti, Buenos Aires, Ed. Universitaria, 1962.

Cartas de Sor María de Agreda y de Felipe IV. Ed. Carlos Seco Serrano, Madrid, Atlas, 1958.

Elogios al Palacio Real del Buen Retiro. Escritos por algunos ingenios de España. Recogidos por Diego de Covarrubias i Leyva, Madrid, Imprenta del Reino, 1935.

Elliott, J. H. y García SANZ, Ángel (coord.), La España del Conde Duque de Olivares. Encuentro Internacional sobre la España del Conde Duque de Olivares celebrado en Toro los días 15-18 de septiembre de 1987, Valladolid, Secretariado de Publicaciones de la Universidad de Valladolid, 1990.

Elliott, J. H., El Conde-Duque de Olivares. El político en una época de decadencia, Barcelona, Crítica, $1991\left(6^{\mathrm{a}}\right)$.

—, La España imperial (1469-1716), Barcelona, Vicens Vives, $1996\left(5^{a}\right)$.

GÉRARD, A., «Pour une phénoménologie du baroque littéraire. Essai sur la tragédie européenne au $\mathrm{XVII}^{\mathrm{e}}$ siècle», Publications de l'Université de l'Etat à Elisabethville, V (1963), pp. 25-65.

GoRDON, Michel D.,«Morality, reform and the empire in seventeenth-century Spain», $I l$ pensiero politico, 11 (1978), pp. 3-19.

JOSA, Lola, «La 'extrañeza' del teatro de Juan Ruiz de Alarcón: una cuestión cervantina», América y el teatro español del Siglo de Oro. II Congreso Iberoamericano de teatro (Cádiz, 23 a 26 de octubre, 1996). Edición a cargo de Concepción Reverte Bernal y Mercedes de los Reyes Peña, Cádiz, Servicio de Publicaciones de la Universidad de Cádiz, 1998, pp. 153-167.

${ }^{65}$ Luis CernudA, Prosa completa, Barcelona, Barral Editores, 1975, p. 1107. 
-, «El semejante a sí mismo de Juan Ruiz de Alarcón: un desafío cervantino», Actas del XIII Congreso de la Asociación Internacional de Hispanistas. (Madrid, 6-11 de 1998). Tomo I (Medieval-Siglos de Oro). Edición de Florencio Sevilla y Carlos Alvar, Madrid, Castalia, 2000, pp. 601-608.

-, El arte dramático de Juan Ruiz de Alarcón, Kassel, Reichenberger (en prensa).

KING, Willard F., Juan Ruiz de alarcón, letrado y dramaturgo. Su mundo mexicano y español, México, El Colegio de México, 1989.

MARIANA, Juan de, Obras del padre Juan de Mariana, Madrid, M. Rivadeneyra, 1854, 2 vols.

METFORD, J. C. J., «Tirso de Molina and the Conde-Duque de Olivares», Bulletin of Hispanic Studies, 36 (1959), pp. 15-57.

NAVARRo DuRÁN, Rosa, «Trazas de Juan Ruiz de Alarcón», El redescubrimiento de los clásicos. Actas de las XV Jornadas de Teatro Clásico. Almagro, julio de 1992, Universidad de Castilla-La Mancha, 1993, pp. 63-75.

—, «Diseños análogos en comedias de Juan Ruiz de Alarcón», Salinas, n. ${ }^{\circ} 15$ (2001), pp. 93-98.

Obras varias al Real Palacio dél Buen Retiro. Recogidas por Manuel de Gallegos, Madrid, María de Quiñones, 1637.

PAZ, Octavio, El laberinto de la soledad, México, Fondo de Cultura Económica, 1993 $\left(15 .{ }^{\mathrm{a}}\right)$.

PÉREZ DE HERRERA, Cristóbal, Amparo de pobres. Edición, introducción y notas de Michel Cavillac, Madrid, Clásicos Castellanos, 1975.

REICHENBERGER, Arnold G., "The Uniqueness of the 'Comedia'», Hispanic Review, XXVII (1959), pp. 303-319.

RUIZ DE AlaRCón, Juan, Las paredes oyen / La verdad sospechosa. Edición, introducción y notas de Juan Oleza y Teresa Ferrer, Barcelona, Planeta, 1986.

-, Obras completas. Introducción y nuevo estudio preliminar de Alba V. Ebersole, Valencia, Albatros Hispanofilia, 1990, 2 vols.

SÉNECA, Cartas a Lucilio, VIII, LXX. Obras completas. Introducción traducción y notas de Lorenzo Riber, Madrid, Aguilar, 1949.

TiRso DE Molina, Historia General de la Orden de Nuestra Señora de las Mercedes. Ed. Fray Manuel Penedo Rey, Madrid, Provincia de la Merced de Castilla, 1973, 2 vols.

YouNG, Richard A., La figura del rey y la institución real en la comedia lopesca, Madrid, José Porrúa Turanzas, 1979. 


\title{
RESUMEN
}

\section{Hacia el pensamiento de Juan Ruiz de Alarcón, por Lola Josa.}

La comedia de caracteres nace en manos de Ruiz de Alarcón porque consigue que, a partir de sus primeras comedias, las de enredo, los protagonistas aprendan a regir sus propias acciones al margen de tipificación alguna. Motivo por el que la crítica, sin entrar en más análisis, haya calificado su teatro como 'moral'. Sin embargo, nos encontramos ante un dramaturgo que escenifica espejismos; desenmascara a tiranos disfrazados de monarcas ecuánimes; frustra la trayectoria de privados egoístas y sedientos de poder o enfermos por sus pasiones; mientras que, al mismo tiempo, la omisión de la providencia se convierte, también, en otra clase de protesta. Toda la corte sobre las tablas para, con ironía, ridiculizar y castigar sus vicios y delirios. Cuando por fin descubrió los de la política del condeduque de Olivares, decidió abandonar el teatro. De este modo se nos descubre a otro Juan Ruiz de Alarcón nunca sospechado: el dramaturgo que creyó en el programa de la reformación que el privado de Felipe IV quiso imponer a una «patria doliente», como el propio dramaturgo denominó a aquella España de la primera mitad del siglo XVII.

Palabras clave: Ruiz de Alarcón, Teatro de la Edad de Oro, Literatura y Sociedad.

\begin{abstract}
The comedy of characters was born in the hands of Ruiz de Alarcón as he achieved that from his first comedies, those of enredo, the main characters learnt to govern their own actions without any classification. That is the reason why the critics, without any further analysis, have described his theatre as 'moral'. Nevertheless, we are talking about a dramatist who stages mirages, unmasks tyrants disguised as level-headed monarchs, and frustrates the development of those court favourites who were egoists and ill by their passions. At the same time, the omission of providence becomes another kind of protest. All the court on the stage to ridicule with irony and punish their bad habits and delusions. When he finally discovered the politics of the conde-duque de Olivares, he decided to give up theatre. Therefore, we discover another Juan Ruiz de Alarcón never suspected: the dramatist who believed in the program of reformation that the conde-duque de Olivares, court favourite of King Philip IV, wanted to impose to a «patria doliente», name given by the dramatist to the Spain of the first half of the 17 th century.
\end{abstract}

Key words: Ruiz de Alarcón, Golden age's theatre, Literature and Society. 